\title{
Application of 3D Music Inventory Control Technique for the Controlled Drugs in Intensive Care Unit of a Tertiary Care Hospital
}

\author{
${ }^{1}$ Sameer Mehrotra, ${ }^{2}$ Sunil Basukala, ${ }^{3}$ Pawan Kapoor, ${ }^{4}$ Sunil Kant, ${ }^{5}$ RK Ranyal, ${ }^{6}$ Punit Yadav \\ ${ }^{7}$ Swati Varshney, ${ }^{8}$ SK Patnaik, ${ }^{9}$ Madhav Madhusudan Singh
}

\section{ABSTRACT}

Approximately $35 \%$ of annual hospitals budget is spent on buying materials and supplies, including medicines. The medical store is one of the most extensively used facilities of the hospital and hence it is essential that health managers use scientific methods to achieve efficient management and patient satisfaction.

Aims and objectives: To apply selective inventory control techniques for the drugs used in intensive care unit of tertiary care teaching hospital.

Materials and methods: The annual consumption and expenditure incurred on each item of controlled drugs in medical intensive care unit (ICU) for the years 2013 to 2014 was analyzed, and inventory control techniques, i.e. ABC, VED and ABC-VED matrix analysis, were applied.

Results: It was observed that 13 medicines (43.33\%) out of 30 were classified in the category1 $(A V+B V+C V+A E+A D)$ for stringent control.

Conclusion: Scientific inventory control management to be applied for efficient management of medical stores.

Keywords: ABC, VED analysis, Inventory control.

How to cite this article: Mehrotra S, Basukala S, Kapoor P, Kant S, Ranyal RK, Yadav P, Varshney S, Patnaik SK, Singh MM. Application of 3D Music Inventory Control Technique for the Controlled Drugs in Intensive Care Unit of a Tertiary

\footnotetext{
${ }^{1}$ Assistant Professor, ${ }^{2,7}$ Resident, ${ }^{3}$ Additional Director General ${ }^{4}$ Deputy Director General, ${ }^{5}$ Professor and Head, ${ }^{6}$ Professor ${ }^{8}$ Joint Director, ${ }^{9}$ Joint Director [Medical Services (Trg) and Faculty]

1,2,5-7 Department of Hospital Administration, Armed Forces Medical College, Pune, Maharashtra, India
}

${ }^{3}$ DGAFMS, M-Block, Ministry of Defence, Government of India New Delhi, India

${ }^{4}$ DGMS, L-Block, Ministry of Defence, Government of India New Delhi, India

${ }^{8}$ DGAFMS, Medical Services, M-Block, Ministry of Defence Government of India, New Delhi, India

${ }^{9}$ DGMS (Army), L-Block, Ministry of Defence, Government of India, New Delhi, India

Corresponding Author: Sameer Mehrotra, Assistant Professor, Department of Hospital Administration, Armed Forces Medical College, Pune, Maharashtra, India, e-mail: sammymdoc@gmail.com
Care Hospital. Int J Res Foundation Hosp Healthc Adm 2015; 3(1):5-9.

\section{Source of support: Nil}

Conflict of interest: None

\section{INTRODUCTION}

Approximately 35\% of annual hospitals budget is spent on buying materials and supplies, including medicines. This requires effective and efficient management of the medical stores. Efficient priority setting, decision making in purchase and distribution of specific drugs, close supervision on drugs belonging to important categories, and prevention of pilferage depend on the drug and inventory management. ${ }^{1}$

Quality of care in tertiary care hospitals is also sensitive to the timely availability of facilities including drugs. The medical store is one of the most extensively used facilities of the hospital and one of the few areas where a large amount of money is spent on purchases on a recurring basis. This emphasizes the need for planning, designing and organizing the medical stores in a manner that results in efficient clinical and administrative services. ${ }^{2}$

The goal of the hospital supply system is to ensure that there is adequate stock of the required items so that an uninterrupted supply of all essential items is maintained. ${ }^{3}$ A study from a 1500-bedded state-funded hospital has claimed that review and control measures for expensive drugs brought about $20 \%$ savings. ${ }^{4}$

Drug inventory management aims at cost containment and improved efficiency. ${ }^{5}$ Inventory control is very essential in a developing country like India. India is a country of scarce resources and it is the primary responsibility of each hospital to ensure optimum utilization of available resources to provide good service or quality patient care. ${ }^{6}$

It is essential that health managers use scientific methods to maximize their returns from investment at a minimal cost. ${ }^{7-9}$

Inventory analysis seeks to achieve maximal output with minimal investment input, based on the economic principle of stretching the limited means to meet unlimited ends. ${ }^{10}$ There is no denying that stocking hospital 
pharmaceuticals and supplies can be expensive and tie up a lot of capital, and bringing efficiencies to such important cost drivers-often 30 to $40 \%$ of a hospital's budget-can present meaningful savings. ${ }^{11}$

Thus, a hospital materials manager must establish efficient inventory system policies for normal operating conditions that also ensure the hospital's ability to meet emergency demand conditions. ${ }^{12}$ Inventory is a necessary part of doing business and provided by most organizations in any sector of economy. ${ }^{13}$

\section{AIMS}

Application of selective inventory control techniques for the drugs used in intensive care unit (ICU) of tertiary care teaching hospital.

\section{OBJECTIVES}

- To identify the categories of drugs in medical ICU which need stringent management control.

- To identify the item categories requiring greater supervisory monitoring.

- Application of collective inventory control techniques to analyze and effectively and efficiently manage medical stores in the ICU.

\section{MATERIALS AND METHODS}

The data of annual consumption and expenditure incurred on each controlled drugs in medical ICU for the financial years 2013 to 2014 were collected from the receipt-expense register. The data were then transcribed in an MS Excel spreadsheet. The statistical analysis was carried out using the MS Excel statistical functions. Annual expenditure for each controlled drug used in ICU were calculated for Jan 2014 to Dec 2014.

\section{ABC Analysis}

$\mathrm{ABC}$ analysis of all the controlled drugs used in the ICU was done. For this, the annual expenditure of individual items was arranged in descending order. The cumulative cost of all the items was calculated. The cumulative percentage of expenditure and the cumulative percentage of number of items were calculated. This list was then subdivided into three categories: $\mathrm{A}, \mathrm{B}$ and $\mathrm{C}$ based on the cumulative cost percentage of 70,20 and $10 \%$ respectively.

\section{VED Analysis}

The VED criticality analysis of all the listed items was performed by classifying the items into vital (V), essential (E) and desirable (D) categories. Intensive care unit (med) panel of specialists were used to decide upon the criticality of items. VED value given as per consensus of more than $50 \%$ members of the specialist panel. The final list of drugs arranged on the basis of criticality by medical experts was analyzed for concurrence of opinion regarding classification.

\section{ABC-VED Matrix}

The ABC-VED matrix was formulated by combining the $\mathrm{ABC}$ and VED analysis to evolve a management system, which can be used for prioritization. From the resultant combination, three categories were classified (I, II and III). Category I was constituted by items belonging to AV, $\mathrm{AE}, \mathrm{AD}, \mathrm{BV}$ and $\mathrm{CV}$ subcategories. The $\mathrm{BE}, \mathrm{CE}$ and $\mathrm{BD}$ subcategories constituted category II, and the remaining items in the CD subcategory constituted category III. In these subcategories, the first alphabet denotes its place in the $\mathrm{ABC}$ analysis, while the second alphabet stands for its place in the VED analysis.

\section{Music 3D}

Drugs with high and low consumption were determined based on ABC analysis. A drugs with $70 \%$ of annual expenditure were considered to be high consumption value and those with $10 \%$ of annual expenditure to be low consumption value. Both high and low consumption items were further classified based on criticality (VED analysis) to avoid any stock outs.

\section{LIMITATIONS OF STUDY}

- Study conducted for only controlled drugs in medical ICU.

- Only medical specialist were discussed for VED analysis.

\section{RESULT AND ANALYSIS}

$\mathrm{ABC}$ analysis of all the controlled drugs used in the ICU as shown in (Table 1).

\section{ABC Distribution Cost}

Distribution of cost of drugs as per $\mathrm{ABC}$ analysis is shown in Graph 1.

\section{VED Analysis}

VED analysis of all the controlled drugs used in medical ICU. VED value given as per consensus of more than $50 \%$ members of the specialist panel as shown in (Table 2).

Number of drugs and percentage of expenditure incurred for the drugs are shown in Graph 2. 
Table 1: $A B C$ analysis of all the controlled drugs used in ICU

\begin{tabular}{|c|c|c|c|c|c|}
\hline \multirow[b]{2}{*}{ SI. no. } & \multirow[b]{2}{*}{ Drug analysis } & \multicolumn{3}{|c|}{ Category } & \multirow[b]{2}{*}{ Total } \\
\hline & & $\bar{A}$ & $B$ & $C$ & \\
\hline 1. & Total annual consumption (\%) & $71.8 \%$ & $19.7 \%$ & $8.5 \%$ & $100 \%$ \\
\hline 2. & Value of annual consumption (₹) & $46,90,296$ & $12,77,075$ & $5,56,229$ & $65,23,600$ \\
\hline 3. & No. of items & 5 & 6 & 19 & 30 \\
\hline 4. & Percentage of items & $17 \%$ & $20 \%$ & $63 \%$ & $100 \%$ \\
\hline
\end{tabular}

Table 2: VED analysis of all the controlled drugs

\begin{tabular}{lll}
\hline Category & No. of drugs & Percentage of total \\
\hline V & 11 & 36.6 \\
E & 10 & 33.3 \\
D & 9 & 30 \\
\hline Total & 30 & 100 \\
\hline
\end{tabular}

\section{ABC-VED Matrix}

The ABC-VED matrix analysis classification of the inventory reveals the nine different subcategories $(\mathrm{AV}, \mathrm{AE}, \mathrm{AD}$, $\mathrm{BV}, \mathrm{BE}, \mathrm{BD}, \mathrm{CV}, \mathrm{CE}$ and $\mathrm{CD}$ ). These nine subcategories (Table 3) were further grouped into three main categoriess: categories I, II and III. Out of the total inventory of 30 drugs, there were five (16.7\%) items in category I, 6 (20\%) items in category II and 19 (63.3\%) items in category III, amounting for $71.9 \%$ (₹ 4,690,296), 19.6\% (₹ 1,277,075) and $63.3 \%$ (₹ $5,56,229$ ) respectively, for each category out of a total budget of ₹ $65,23,600 /$ - of the medical stores.

\section{CATEGORY-WISE COST DISTRIBUTION}

Graphs 3 and 4 show cost distribution for each category and graphical representation of cost.

\section{DISCUSSION}

ABC analysis of controlled drugs used in ICU of 1000 bedded tertiary care hospitals revealed that out of 30 items in the drug list worth ₹ 65,23,600 considered for the study, $17 \%$ (5), 20\% (6) and 63\% (19) items were found to be $\mathrm{A}, \mathrm{B}$ and $\mathrm{C}$ category items, respectively, amounting for $71.80 \%$ (₹ 46,90,296.00/-), 19.70\% (₹ 12,77,075.00/-) and $8.5 \%$ (₹ 5,56,229.00/-) of ADE of the medical stores.

VED analysis revealed that vital items (V) accounted for $36.60 \%$ (11), essential items (E) accounted for $33.60 \%$ (10) and desirable items accounted for 30\% (9). The total value of drugs in each category I, II and III were $82.40 \%$ (₹ $53,72,070.00 /-), 14.90 \%$ (₹ $9,73,800.00 /-$ ) and $2.70 \%$

Table 3: The ABC-VED matrix analysis

\begin{tabular}{|c|c|c|c|c|}
\hline$A B C$ & V & $E$ & $D$ & Total \\
\hline \multirow[t]{2}{*}{ A } & AV (2 items) $6.7 \%$ & $\mathrm{AE}(2$ items) $6.7 \%$ & AD (1 item) 3.3\% & (5 items) $16.7 \%$ \\
\hline & ₹ $22,02,600$ (33.8\%) & ₹ $21,00,120$ (32.2\%) & ₹ $3,87,576(5.9 \%)$ & ₹ $46,90,296 /-(71.9 \%)$ \\
\hline \multirow[t]{2}{*}{ B } & BV (2 items) $6.7 \%$ & $\mathrm{BE}(3$ items) 10\% & BD (1 item) 3.3\% & (6 items) $20 \%$ \\
\hline & ₹ $5,15,900$ (7.9\%) & ₹ $5,10,600(7.8 \%)$ & ₹ $2,50,575(3.8 \%)$ & ₹ 12,77,075/- (19.6\%) \\
\hline \multirow[t]{2}{*}{ C } & CV (7 items) $23.3 \%$ & CE (5 items) $16.7 \%$ & CD (7 items) $23.3 \%$ & (19 items) 63.3\% \\
\hline & ₹ 1,65,874 (2.5\%) & ₹ $2,12,625$ (3.3\%) & ₹ $1,77,730(2.7 \%)$ & ₹ 556229/- (8.5\%) \\
\hline \multirow[t]{2}{*}{ Total } & (11 items) $36.7 \%$ & (10 items) $33.4 \%$ & (9 items) 29.9 & (30 items) 100\% \\
\hline & ₹ 28,84,374/- & ₹ $28,23,345 /-$ & ₹ $8,15,881$ & $₹ 65,23,600 /-$ \\
\hline
\end{tabular}

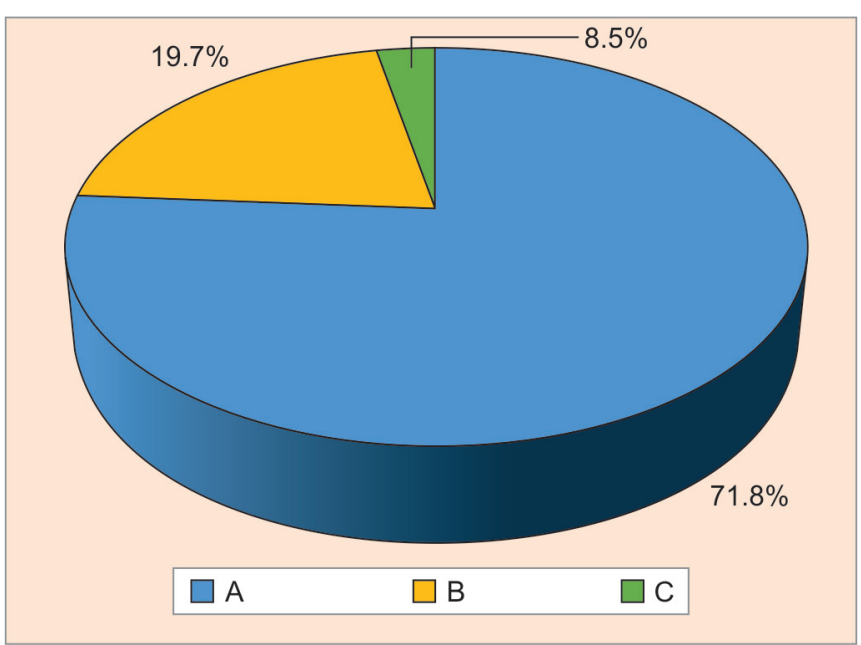

Graph 1: Distribution of cost of drugs as per $A B C$ analysis

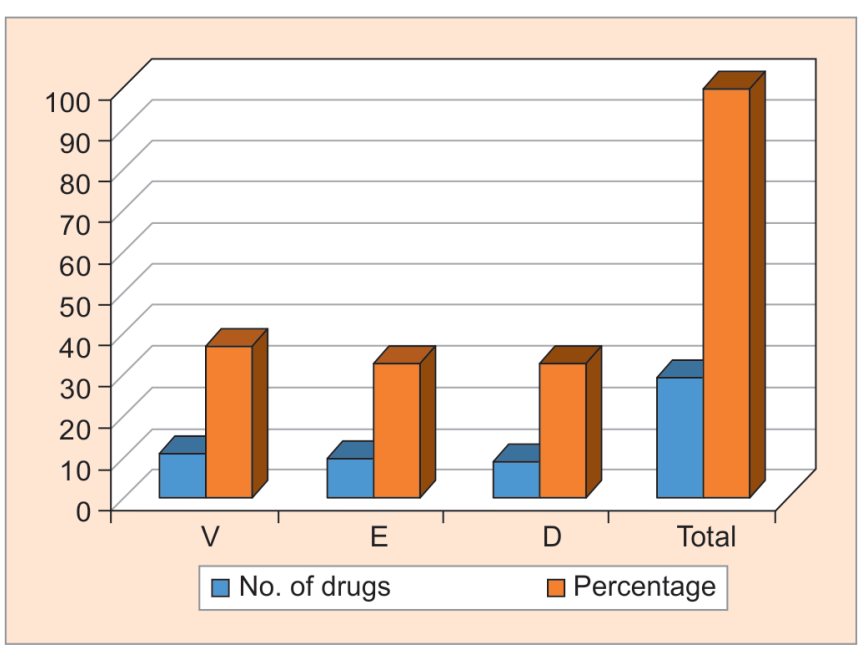

Graph 2: Number of drugs and percentage of expenditure incurred for the drugs 


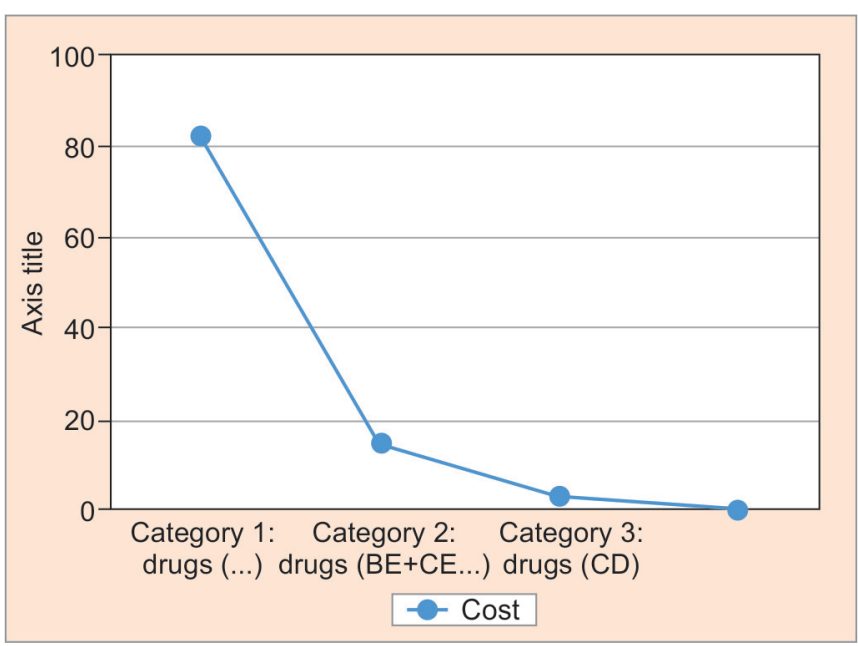

Graph 3: Percentage cost distribution for each category of the drugs

(₹ 1,77,730.00/-) of total annual drug expenditure (ADE) of the medical stores respectively. The result of the present study in comparison with similar studies ${ }^{14}$ (Table 4).

If $\mathrm{ABC}$ analysis was alone considered for inventory control, it would have taken care of just $6.77 \%$ of the drugs pertaining to category $\mathrm{A}$. This would have completely neglected the vital drugs from category $B$ and $C$ which comprises of $11.47 \%$. Similarly if only criticality factor VED analysis) was taken as a basis for inventory control, ideal control can be exercised only on the identified vital and/or essential items accounting for $69.51 \%$ (1076). However, this would have easily missed the category A items in the desirable group. Hence an inventory control method which takes into consideration both the cost factor and the criticality factor (Table 5) proves to be a better method for efficient control of inventory.

It is quite evident from the results of the present study that the combination of $\mathrm{ABC}$ and VED analysis, in terms

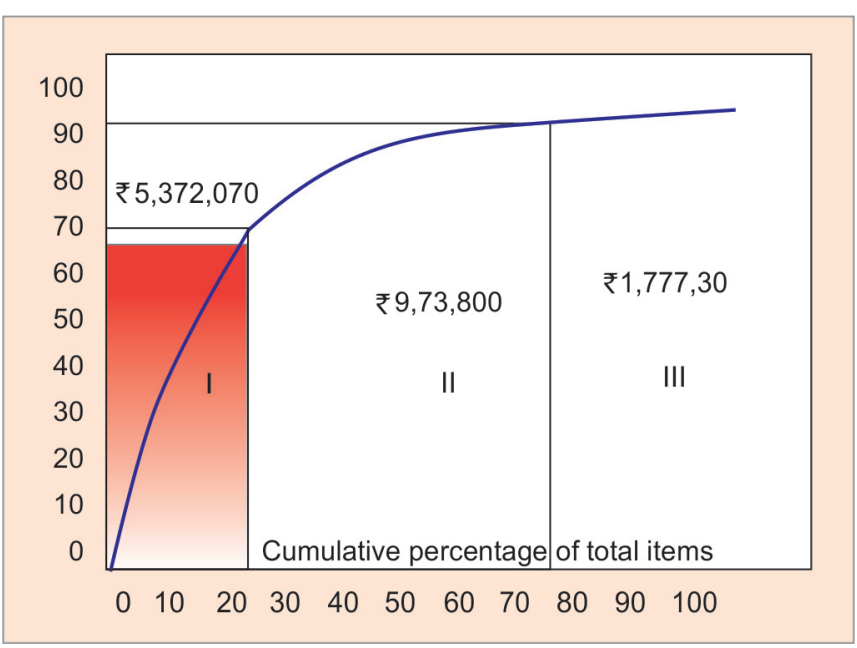

Graph 4: ABC-VED matrix analysis

of the $\mathrm{ABC}$ matrix enhances the ability to narrow down our attention on 13 items belonging to category I for strict managerial control; these items are either costly or vital. The annual expenditure of category I items was $82.40 \%$ of annual drug expenditure of the medical store. Category II items represent $14.90 \%$ of the ADE. Category III items consume $2.70 \%$ of the ADE. Hence, based on ABC and VED analysis various inventory management functions can be performed by managers at different levels (Table 6).

In addition, application of multiunit selective inventory control analysis (MUSIC 3D) method of inventory control can also be applied in the same matrix which enables a better and more stringent management of the inventory to prevent stock out (Table 7). The control criteria of three dimensions are finance, operations and material. Hence, this approach ensures a simple method of fixing ideal stock level of each drugs taking into account of criticality, availability and consumption value (Table 8 ).

Table 4: Comparison of various Indian studies with present study

\begin{tabular}{llllll}
\hline Category & $\begin{array}{l}\text { Neuropsychiatry } \\
\text { hospital, New Delhi }\end{array}$ & GMCH, Goa study & $\begin{array}{l}\text { PGI, Chandigarh } \\
\text { study }\end{array}$ & AFMS study & Present study \\
\hline A & 3.45 & 12.93 & 13.78 & 14.46 & 17 \\
B & 6.9 & 19.54 & 21.85 & 22.46 & 20 \\
C & 89.65 & 67.53 & 64.37 & 63.08 & 63 \\
V & 32.41 & 12.36 & 12.11 & 7.39 & 36.6 \\
E & 61.38 & 47.12 & 59.33 & 49.23 & 33.3 \\
D & 6.2 & 40.52 & 28.51 & 43.38 & 30.0 \\
I & 33.8 & 22.99 & 22.09 & 20.92 & 82.4 \\
II & 60 & 41.67 & 54.63 & 48.92 & 14.9 \\
III & 6.2 & 35.34 & 23.28 & 30.16 & 2.7 \\
\hline
\end{tabular}

Table 5: Categorization of the drugs

\begin{tabular}{lllll}
\hline Category & Comprise & Drugs (no.) & Percentage of cost & Cost (₹) \\
\hline I & AV + AE + AD + BV + CV & 13 & 82.4 & $53,72,070$ \\
II & BE + CE + BD & 10 & 14.9 & $9,73,800$ \\
III & CD & 7 & 2.7 & $1,77,730$ \\
\hline
\end{tabular}


Table 6: Inventory management

\begin{tabular}{|c|c|c|c|}
\hline Functions & Category I & Category II & Category III \\
\hline Forecasting & Accurate & Accurate & Approximate \\
\hline Budget control & Close check & $\begin{array}{l}\text { Reasonable } \\
\text { check }\end{array}$ & No check \\
\hline $\begin{array}{l}\text { Pre purchase } \\
\text { functions }\end{array}$ & $\begin{array}{l}\text { Maximum } \\
\text { attention }\end{array}$ & $\begin{array}{l}\text { Some } \\
\text { attention }\end{array}$ & Least attention \\
\hline Negotiations & $\begin{array}{l}\text { Top } \\
\text { management }\end{array}$ & $\begin{array}{l}\text { Middle } \\
\text { management }\end{array}$ & $\begin{array}{l}\text { Lower } \\
\text { management }\end{array}$ \\
\hline Follow-up & Regular & Infrequent & Rare \\
\hline Inspection & Close control & Simple check & Visual check \\
\hline $\begin{array}{l}\text { Inventory } \\
\text { control }\end{array}$ & Constant & Vigilant & Routine \\
\hline Level of control & Top & Middle & Storekeeper \\
\hline Review & Monthly & 3 monthly & Yearly \\
\hline Safety stock & Minimum & Reasonable & Large \\
\hline Order quantity & Fixed EOQ & Fixed $E O Q$ & Fixed ROL \\
\hline Stock taking & Frequent & Less frequent & Least frequent \\
\hline
\end{tabular}

Table 8: Inventory management by application of music 3D

\begin{tabular}{|c|c|c|}
\hline & Category & Management \\
\hline & 1 and 2 & $\begin{array}{l}\text { a. Service level-100\% to be maintained } \\
\text { b. Cannot go for bulk purchase } \\
\text { c. Inventory control-top management } \\
\text { d. Reorder level is to be maintained } \\
\text { e. Effort to bring down lead time }\end{array}$ \\
\hline & 3 and 4 & $\begin{array}{l}\text { a. Stockless purchasing } \\
\text { b. Safety stock can be maintained using } \\
\text { long lead time } \\
\text { c. Efforts to bring lead time } \\
\text { d. Can go for bulk discount during } \\
\text { purchasing }\end{array}$ \\
\hline & 5 & $\begin{array}{l}\text { a. Strict inventory control } \\
\text { b. Frequent order } \\
\text { c. Consult reorder plan }\end{array}$ \\
\hline 4. & & a. Purchase order \\
\hline 5. & 7 & a. Bulk purchase \\
\hline 6. & 8 & $\begin{array}{l}\text { a. Purchase at regular interval } \\
\text { b. Bulk purchase } \\
\text { c. Avoid expiry }\end{array}$ \\
\hline
\end{tabular}

\section{CONCLUSION}

This study analyzed the inventory control method taking into account the controlled drug list of a tertiary care service hospital. Sound inventory control method is of utmost importance in efficient management of the scarce resource in the healthcare setting. Moreover, sound inventory control method will facilitate the management in controlling the cost and also ensure the timely availability of vital and essential items in the hospital which will definitely go a long way in achieving patient satisfaction and even patient delight.
Table 7: Music 3D value

\begin{tabular}{lllll}
\hline & \multicolumn{2}{l}{$\begin{array}{l}\text { High consumption } \\
\text { value }\end{array}$} & $\begin{array}{l}\text { Low consumption } \\
\text { value }\end{array}$ \\
\hline Critical & LLT & SLT & LLT & SLT \\
& Critical & Critical & Critical & Critical \\
& LLT & SLT & LLT & SLT \\
& HCV & HCV & LCV & LCV \\
& 1 & 2 & 3 & 4 \\
Noncritical & N critical & N critical & N critical & N critical \\
& LLT & SLT & LLT & SLT \\
& HCV & HCV & LCV & LCV \\
& 5 & 6 & 7 & 8 \\
\hline
\end{tabular}

LLT: Low lead time; SLT: Short lead time; HCV: High consumption value; LCV: Low consumption value

\section{REFERENCES}

1. Doshi RP, Patel N, Jani N, Basu M, Mathew, Simy. ABC and VED analyses of drug management in a government tertiary care hospital in Kerala. iHEA 2007 6th World Congress: Explorations in Health Economics Paper; 2007. p. 201-205.

2. Kunders GD, Gopinath S, Katakam A. Planning and designing supportive services-Pharmacy. Hospitals: Planning, Design and Management. New Delhi: Tata McGraw-Hill Publishing Company Limited; 2000. p. 273-281.

3. Kidwai M. Inaugural address. Logistics and supply management for health and family planning programme: a report of intercountry course. National Institute of Health and Family Welfare: New Delhi; 1992. p. 66-70.

4. Pillans PI, Conry I, Gie BE. Drug cost containment at a large teaching hospital. Pharmacoeconomics 1992;1:377-382.

5. Thawani VR, Turankar AV, Sontakke SD, Pimpalkhute SV, Dakhale GN, Jaiswal KS, et al. Economic analysis of drug expenditure in Government Medical College Hospital, Nagpur. Ind J Pharmacol 2004;36:15-19.

6. Gupta S, Kant S. Inventory control. Hospital stores management-an integrated approach. New Delhi: Jaypee Brothers Medical Publishers (P) Ltd.; 2000. p. 60-72.

7. Ramanathan R. ABC inventory classification with multiplecriteria using weighted linear optimization. Computers and Operations Res 2006;33:695-700.

8. Das JK. Inventory control. In: Kaushik M, Agarwal AK, Arora SB, editors. Essentials of Logistics and Equipment Managemnt, Manual of Post Graduate Diploma in Hospital and Health Management. Indira Gandhi National Open University, School of Health Sciences, New Delhi; 2001. p. 201-205.

9. Gopalakrishnan P, Sundaresan M. Material management: An integrated approach. New Delhi: Prentice Hall; 1985. p. 15-19.

10. Beier FJ. The Management of the supply chain for hospital pharmacies: A focus on inventory management practices. Journal of Business Logistics 1995;16:153-177.

11. Anonymous. Supply chain: Cost of goods grab executives' attention. Health Facilities Management 2008;21:26-28.

12. Duclos LK. Hospital inventory management for emergency demand. J Supply Chain Management 1993;29:29-38.

13. Stock, James R, Lambert DM. Inventory serves five purposes within the firm. J Business Logistics 2001;10:19-25.

14. Khurana $S$, et al. Inventory control techniques in medical stores of a tertiary care neuropsychiatry hospital in Delhi. Health 2013;5:8-13. 